\title{
Propioniciclava tarda gen. nov., sp. nov., isolated from a methanogenic reactor treating waste from cattle farms
}

\author{
Correspondence \\ Atsuko Ueki \\ uatsuko@tds1.tr.yamagata-u.ac.jp
}

\author{
Yoshimichi Sugawara, ${ }^{1}$ Atsuko Ueki, ${ }_{1}^{1}$ Kunihiro Abe, ${ }^{1}$ Nobuo Kaku, ${ }^{1}$ \\ Kazuya Watanabe ${ }^{2}$ and Katsuji Ueki ${ }^{1}$ \\ ${ }^{1}$ Faculty of Agriculture, Yamagata University, Wakaba-machi 1-23, Tsuruoka 997-8555, Japan
2Exploratory Research for Advanced Technology (ERATO), JST, University of Tokyo, 7-3-1 Hongo,
Bunkyo-ku, Tokyo 113-8656, Japan
}

\begin{abstract}
Two facultatively anaerobic bacterial strains, designated WR061 ${ }^{\top}$ and WR054, were isolated from rice-straw residue in a methanogenic reactor treating waste from cattle farms in Japan. The two strains were phylogenetically positioned close to one another and had almost the same phenotypic properties. Cells were Gram-reaction-positive, non-motile, non-spore-forming, irregular rods. Cobalamin (vitamin $B_{12}$ ) was required for growth. The strains utilized various carbohydrates, including hexoses and disaccharides, and produced acetate and propionate from these carbohydrates. Pentoses and polysaccharides were not utilized. They grew at $20-37^{\circ} \mathrm{C}$ (optimum $35{ }^{\circ} \mathrm{C}$ ) and $\mathrm{pH}$ 5.3-8.0 (optimum pH 6.8-7.5). Catalase and nitrate-reducing activities were detected. Aesculin was hydrolysed. The major cellular fatty acids were anteiso- $\mathrm{C}_{15: 0}$ and $\mathrm{C}_{15: 0}$ DMA, the major respiratory quinone was menaquinone MK- $9\left(\mathrm{H}_{4}\right)$ and the genomic DNA $\mathrm{G}+\mathrm{C}$ content was $69.3-69.5 \mathrm{~mol} \%$. The diagnostic diamino acid in the peptidoglycan was meso-diaminopimelic acid. Phylogenetic analysis based on 16S rRNA gene sequences placed the strains in the phylum Actinobacteria. Both strains were remotely related to the species in the family Propionibacteriaceae and Propionibacterium propionicum JCM 5830 ${ }^{\top}$ was the most closely related type strain with a sequence similarity of $91.6 \%$. Based on phylogenetic, physiological and chemotaxonomic analyses, the two novel strains together represent a novel species of a new genus, for which the name Propioniciclava tarda gen. nov., sp. nov. is proposed. The type strain is $\mathrm{WRO}^{\top} 1^{\top}\left(=\mathrm{JCM} 15804^{\top}=\mathrm{DSM} 22130^{\top}\right)$.
\end{abstract}

Propionate is one of the major volatile fatty acids produced by fermentative bacteria during anaerobic decomposition of organic matter in methanogenic ecosystems. It often accumulates in methanogenic reactors, causing a $\mathrm{pH}$ decrease and an instability of the system (Dolfing, 1988; Ueki et al., 1986). In this study, we describe a novel, facultatively anaerobic, propionate-producing bacterium that was isolated from a methanogenic reactor treating cattle waste.

Strain WR061 ${ }^{\mathrm{T}}\left(=\mathrm{JCM} \quad 15804^{\mathrm{T}}=\mathrm{DSM} 22130^{\mathrm{T}}\right)$ and WR054 (=JCM 15805) were isolated by using the anaerobic roll-tube method (Holdeman et al., 1977) from a sample of rice-straw residue obtained from a methanogenic reactor treating waste collected from cattle farms (housing up to 1000 cattle in total) in Betsukai-machi, Hokkaido,

Abbreviations: DMA, dimethylacetal; DAP, diaminopimelic acid.

The GenBank/EMBL/DDBJ accession numbers for the 16S rRNA gene sequences of strains $\mathrm{WRO61}^{\top}$ and WR054 are AB298731 and AB298730, respectively.
Japan (Nishiyama et al., 2009a, b; Ueki et al., 2008, 2011). The reactor was of the vertical cylindrical type $\left(1500 \mathrm{~m}^{3}\right)$ and was operated at $35{ }^{\circ} \mathrm{C}$. Rice straw is used as matting at the cattle farms and the spent straw, containing cattle faeces and urine, is thrown into the reactor and treated as waste. The rice-straw residue samples obtained from the reactor were washed several times with sterile anoxic diluent and homogenized in a Waring blender (10000 r.p.m. for $10 \mathrm{~min}$ ) under $\mathrm{N}_{2}$ atmosphere. The homogenized samples were successively diluted (10-fold) under anaerobic conditions and used as inocula for anaerobic roll-tubes containing PY4S medium supplemented with a vitamin B mixture (PYV4S) (Akasaka et al., 2004). Colonies that formed on the agar were picked at random after incubation for 2 weeks at $30{ }^{\circ} \mathrm{C}$ and about 50 isolates were obtained from a sample. Strains $\mathrm{WR} 061^{\mathrm{T}}$ and WR054 were picked from a roll-tube inoculated with a $10^{-4}$ diluted sample.

Both strains were cultivated anaerobically at $30{ }^{\circ} \mathrm{C}$ unless otherwise stated using peptone-yeast extract (PY) medium 
(Holdeman et al., 1977) as the basal medium with oxygenfree mixed gas $\left(\mathrm{N}_{2} / \mathrm{CO}_{2}, 95: 5\right)$ as the headspace, as described by Ueki et al. (2008). PY medium supplemented with $\left(1^{-1}\right) 0.25 \mathrm{~g}$ each of glucose, cellobiose, maltose and soluble starch as well as $15 \mathrm{~g}$ agar (Difco) was designated PY4S agar and was used for maintenance of the strains in agar slants. PY liquid medium supplemented with the vitamin $\mathrm{B}$ mixture (PYV medium) or cobalamin $\left(\mathrm{PYB}_{12}\right.$ medium) was used as a basal medium for cultivation under various conditions. $\mathrm{PYB}_{12}$ medium contained cyanocobalamin (cobalamin or vitamin $B_{12}$ ) as a sole vitamin, which was added at the same concentration $\left(10 \mu \mathrm{g} \mathrm{l}^{-1}\right)$ as that in the vitamin $\mathrm{B}$ mixture (Akasaka et al., 2004), and $\mathrm{PYB}_{12}$ medium containing $10 \mathrm{~g}$ glucose $1^{-1}\left(\mathrm{PYB}_{12} \mathrm{G}\right.$ medium) was used for cultivation of the strains for various physiological and chemotaxonomic tests. Cells previously transferred at least twice in the medium containing the vitamin mixture or cobalamin were used as inocula for various cultivation experiments. Except for when $\mathrm{pH}$ range for growth was being determined, the $\mathrm{pH}$ of the media was adjusted to $\mathrm{pH} 7.4-7.5$, since the strains preferred slightly alkaline conditions. Growth in liquid media was monitored by changes in $\mathrm{OD}_{660}$. The reference type strain of the closest related species, Propionibacterium propionicum JCM $5830^{\mathrm{T}}$, was cultivated under the same conditions using the same media adjusted to $\mathrm{pH}$ 7.0.

Growth of the strains under aerobic conditions was examined as described previously (Ueki et al., 2008). Spore formation was assessed by observation of cells after Gram staining and the production of thermotolerant cells was determined by cultivating heat-treated $\left(80{ }^{\circ} \mathrm{C}\right.$ for $10 \mathrm{~min}$ ) cells in $\mathrm{PYB}_{12} \mathrm{G}$ liquid medium. The motility of cells was examined from both slant and liquid cultures using phase-contrast microscopy. Oxidase and nitratereducing activities were determined according to the methods described by Akasaka et al. (2003). Catalase activity was determined by bubble production from cells cultivated in liquid media, collected by centrifugation and mixed with a small amount of $\mathrm{H}_{2} \mathrm{O}_{2}$ solution $(3 \%$, v/v) (Wilkins et al., 1978). Growth was determined at $10-45{ }^{\circ} \mathrm{C}$ (at $5{ }^{\circ} \mathrm{C}$ intervals and at $37^{\circ} \mathrm{C}$ ), at $\mathrm{pH} 4.0,5.3,5.8,6.8,7.5$, 8.0, 9.2 and 10.2 (values verified after autoclaving), and in the presence of $0-5 \%(\mathrm{w} / \mathrm{v}) \mathrm{NaCl}($ at $1 \%$ intervals and at $0.5 \%)$ in $\mathrm{PYB}_{12} \mathrm{G}$ medium. Bicine $[N, N$-bis (2-hydroxyethyl)glycine] (Good's buffer; Dotite) $(20 \mathrm{mM})$ was used to adjust the media to $\mathrm{pH} 8.0$ and above using $\mathrm{N}_{2}$ gas as the headspace (Ueki et al., 2008). Growth in liquid medium was monitored by changes in $\mathrm{OD}_{660}$. Utilization of carbon sources was tested in $\mathrm{PYB}_{12}$ medium, each substrate being added at $10 \mathrm{~g} \mathrm{l}^{-1}$ (for sugars and sugar alcohols) or $5 \mathrm{~g} \mathrm{l}^{-1}$ for cellulose (filter paper) and xylan. Organic acids were added at final concentrations of $30 \mathrm{mM}$. Utilization of each substrate was determined from measuring growth $\left(\mathrm{OD}_{660}\right)$ (except xylan and filter paper) as well as by detecting fermentation products in the medium after cultivation. Fermentation products were analysed by GC as described previously (Ueki et al., 1986). Production of urease, hydrogen sulfide and indole as well as hydrolysis of aesculin and gelatin was tested according to the methods described by Holdeman et al. (1977). Bile sensitivity was determined in $\mathrm{PYB}_{12} \mathrm{G}$ medium supplemented with 0.1$2.0 \%(\mathrm{w} / \mathrm{v})$ Oxgall (Difco). All experiments for biochemical characterization were performed in duplicate.

Strains WR061 ${ }^{\mathrm{T}}$ and WR054 grew poorly as colonies with slightly dry surfaces on PY4S agar slants. Cells were Gramreaction-positive and non-motile and, when grown on PY4S agar, were irregular and wedge-shaped rods usually occurring in pairs or chains with irregular V-shaped cell arrangements (Fig. 1a). Cells were $0.5-0.8 \times 0.6-1.8 \mu \mathrm{m}$ in size. Spore formation was not observed and cells did not grow after heat treatment. The strains grew aerobically on either PY4S or nutrient agar. Cell morphology when grown under aerobic conditions was the same as when grown under anaerobic conditions.

Growth of both strains in PY or PYG liquid medium was poor but the addition of B-vitamin mixture (PYVG) stimulated the growth. Cobalamin showed almost the same effect on growth, indicating that both strains required cobalamin for growth. Thus, physiological characteristics of the strains were determined in the presence of cobalamin $\left(\mathrm{PYB}_{12}\right.$ medium). Growth rates of both strains, however, were rather low, even in the presence of the vitamin mixture or cobalamin. Increase in the concentration of cobalamin (up to $100 \mu \mathrm{g} \mathrm{l}^{-1}$ ) did not improve growth. When cells grown on PY4S agar slants were directly inoculated to $\mathrm{PYB}_{12} \mathrm{G}$ liquid medium, the cultures took 12 days to reach early stationary phase, whereas this time was shortened to 3-4 days when cells cultivated on PYV4S slants were used as an inoculum. Cells grown in PYV4S agar were slender and longer $(3-6 \mu \mathrm{m})$ than those grown in PY4S agar and often formed irregular and

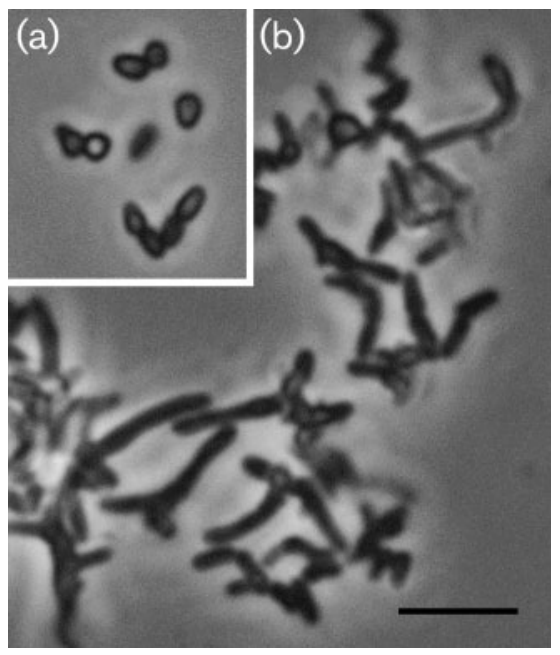

Fig. 1. Phase-contrast photomicrographs of cells of strain WR061 ${ }^{\top}$ grown on PY4S agar (a) and PYV4S agar (b). Bar, $5 \mu \mathrm{m}$. 
crescent-shaped arrangements. Mycelial forms were not observed (Fig. 1b).

The temperature range for growth was $20-37{ }^{\circ} \mathrm{C}$ (optimum $35{ }^{\circ} \mathrm{C}$ ) with very weak growth occurring at $37{ }^{\circ} \mathrm{C}$. The strains grew at $\mathrm{pH}$ 5.3-8.0 and, although the growth rates were almost the same at the $\mathrm{pH}$ range of $6.8-7.5$, the highest growth yield was obtained at $\mathrm{pH} 7.5$ (based on $\left.\mathrm{OD}_{660}\right)$. The final $\mathrm{pH}$ of the media after growth with glucose was $\mathrm{pH} 4.8-4.9$. The highest growth rate $(\mu)$ obtained under the optimum $\mathrm{pH}$ and temperature was $0.05-0.07 \mathrm{~h}^{-1}$. The $\mathrm{NaCl}$ concentration range for growth was $0-0.5 \%(\mathrm{w} / \mathrm{v}) \mathrm{NaCl}$; concentrations of $0.5 \%(\mathrm{w} / \mathrm{v})$ $\mathrm{NaCl}$ and above strongly suppressed growth. Aesculin was hydrolysed. Catalase activity was detected in cells grown in PY4S agar slants or in $\mathrm{PYB}_{12} \mathrm{G}$ medium. Nitrate-reducing activity was detected. The strains did not tolerate bile, even $0.1 \%(\mathrm{w} / \mathrm{v})$ Oxgall. Other physiological characteristics are given in the species description.

The strains utilized fructose, galactose, glucose, cellobiose, lactose and salicin. The strains also utilized mannose, maltose, melibiose, sucrose, trehalose, melezitose, raffinose, mannitol, amygdalin, aesculin, pyruvate and lactate; however, growth on these substrates was delayed compared with the substrates listed previously. The strains did not utilize pentoses, polysaccharides or sugar alcohols. Other substrates tested but not used by the strains are shown in the species description.

Strain WR061 ${ }^{\mathrm{T}}$ produced acetate $\left(1.1 \mathrm{mmol} \mathrm{l}^{-1}\right)$ and propionate $\left(2.4 \mathrm{mmol} \mathrm{l} \mathrm{l}^{-1}\right.$ ) from $\mathrm{PYB}_{12}$ medium and produced acetate $\left(16.0 \mathrm{mmol} \mathrm{l}{ }^{-1}\right)$ and propionate $(25.5$ mmol $~^{-1}$ ) with a trace amount of succinate (1.5 mmol $\mathrm{l}^{-1}$ ) from $\mathrm{PYB}_{12} \mathrm{G}$ medium. Almost the same amounts of products were formed from other substrates utilized (the molar ratio of acetate and propionate being $\sim 1: 2$ ). When grown on lactate $(30 \mathrm{mM})$, acetate $\left(14.3 \mathrm{mmol} \mathrm{l}^{-1}\right)$ and propionate $\left(34.4 \mathrm{mmol} \mathrm{l}^{-1}\right)$ were detected in the medium. Strain WR054 produced almost the same amounts of products from various substrates. The requirement for exogenous cobalamin to grow and produce propionate has been reported for fermentative bacterial species isolated from irrigated rice-field soil (Akasaka et al., 2003) and a methanogenic reactor (Ueki et al., 2008, 2011). Cobalamin is essential for methylmalonyl-CoA isomerase to catalyse propionate production in the methylmalonyl-CoA pathway (Roth et al., 1996).

DNA samples extracted from cells of the novel strains and the almost-complete 16S rRNA gene sequences were PCR amplified using the primer pair $8 \mathrm{f}$ and $1546 \mathrm{r}$ as described previously (Akasaka et al., 2003). The PCR-amplified 16S rRNA genes were sequenced by using an ABI Prism BigDye Terminator Cycle Sequencing ready reaction kit and an ABI Prism 3730 automatic DNA sequencer (Applied Biosystems). Multiple alignments of the amplified sequences with reference sequences in GenBank were performed with the BLAST program (Altschul et al., 1997). A phylogenetic tree was reconstructed by using the neighbour-joining method (Saitou \& Nei, 1987) in the CLUSTAL W program (Thompson et al., 1994) and the maximum-likelihood method (DNAML) in the PHYLIP 3.66 package (Felsenstein, 2006). All gaps and unidentified base positions in the alignments were excluded before sequence assembly. The sequence length produced was $1453 \mathrm{bp}$ for strain WR061 ${ }^{\mathrm{T}}$ and $1448 \mathrm{bp}$ for strain WR054. There were two mismatches between the two sequences and the sequence of $\mathrm{WR}^{0} 01^{\mathrm{T}}$ had one gap. 16S rRNA gene sequence similarity between the two strains was $99.86 \%$. Phylogenetic analysis based on 16S rRNA gene sequences placed both strains in the phylum Actinobacteria. They were affiliated with the family Propionibacteriaceae in the order Actinomycetales (Garrity \& Holt, 2001). The species most closely related to both strains was $P$. propionicum (Charfreitag et al., 1988; Cummins \& Johnson, 1986; Gerencser \& Slack, 1967; Schaal, 1986), originally isolated from a case of human lacrimal canaliculitis, with a $16 \mathrm{~S}$ rRNA gene sequence similarity of $91.6 \%$ between $P$. propionicum JCM $5830^{\mathrm{T}}$ and the two novel strains. Propionibacterium avidum ATCC $25577^{\mathrm{T}}$ (Cummins \& Johnson, 1986) was the next closely related type strain (sequence similarity $91.2 \%$ ). Both novel strains formed a distinct branch in the phylogenetic tree reconstructed using the neighbour-joining method (Fig. 2). When evaluated by using the maximum-likelihood method (data not shown), the tree topology was essentially the same as that obtained with the neighbour-joining method.

The two novel strains and the type strain of their closest relative $\left(P\right.$. propionicum $\mathrm{JCM} 5830^{\mathrm{T}}$ ) were cultivated under the same conditions. Their cellular fatty acids were converted to methyl esters according to the method of Miller (1982) and analysed by GC (HP6890; Hewlett Packard or G-3000; Hitachi) equipped with a HP Ultra 2 column. Fatty acid methyl esters were identified from equivalent chain-lengths (ECL) (Miyagawa et al., 1979) according to the protocol of TechnoSuruga (Shimidu, Japan) (Moore et al., 1994). Both novel strains had almost the same fatty acid composition (Table 1). The major fatty acids of strains WR061 ${ }^{\mathrm{T}}$ and WR054 were anteiso- $\mathrm{C}_{15: 0}$ ( $34.0 \%$ for both strains), $\mathrm{C}_{15: 0}$ dimethylacetal (DMA) (10 and $14.0 \%$, respectively) and anteiso- $\mathrm{C}_{15: 0}$ DMA (6.7 and $9.2 \%)$. The total percentages of $\mathrm{C}_{15: 0}$ compounds in strains WR061 ${ }^{\mathrm{T}}$ and WR054 were 72.6 and $70.0 \%$, respectively. Various DMA-type components were detected; the total amounts of DMA type components in strains WR061 ${ }^{\mathrm{T}}$ and WR054 were 38.3 and $31.8 \%$, respectively. Unsaturated fatty acids were not detected. The major fatty acids of the closest relative, $P$. propionicum JCM $5830^{\mathrm{T}}$, were anteiso- $\mathrm{C}_{15: 0}$ $(32.5 \%)$, iso- $\mathrm{C}_{15: 0}(31.0 \%)$ and $\mathrm{C}_{19: 0}$ cyclo DMA (ECL 19.322) (20.3\%). The presence of branched-chain $C_{15: 0}$ compounds as major components was common to the three strains; however, the overall profile of $P$. propionicum JCM $5830^{\mathrm{T}}$ was significantly different from those of the novel strains; the presence of cyclo-type fatty acids has not been reported in P. propionicum (Charfreitag et al., 1988; Cummins \& Moss, 1990; Kusano et al., 1997; Schaal, 1986). 


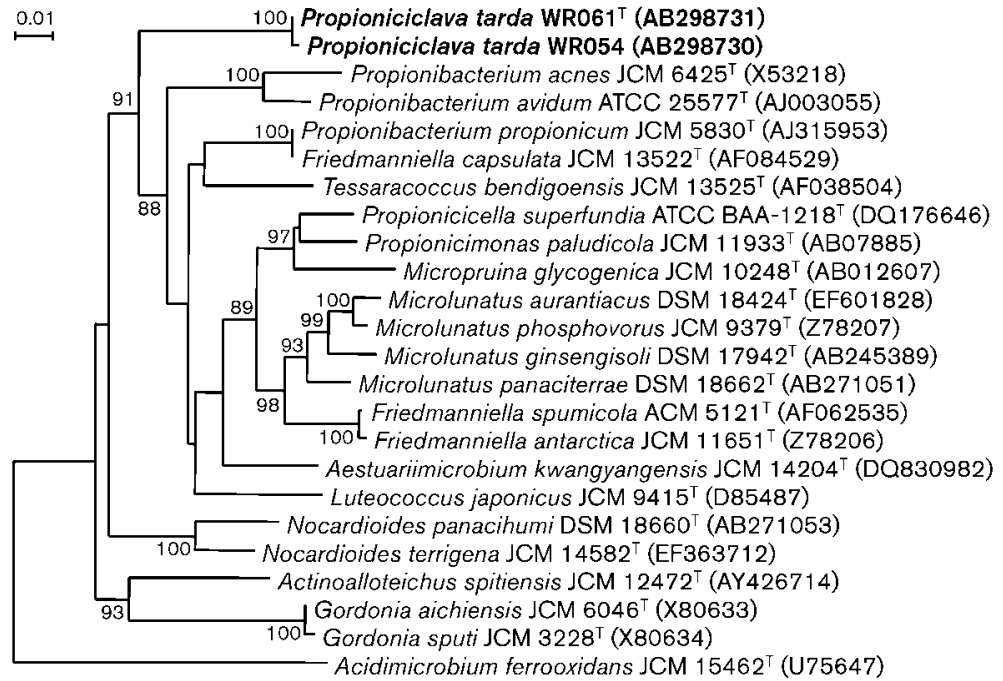

Fig. 2. Neighbour-joining tree based on $16 \mathrm{~S}$ rRNA gene sequences showing the phylogenetic position of novel strains WR061 ${ }^{\top}$ and WR054, other species in the family Propionibacteriaceae and some representative type species of other families in the order Actinomycetales. Bootstrap values $>70 \%$ (based on 1000 replications) are shown at branch nodes. Acidimicrobium ferroxidans JCM $1546^{\top}$ was used as the outgroup. The tree topology evaluated by using the maximumlikelihood method (data not shown) was almost the same as that obtained with the neighbourjoining method. Bar, 0.01 substitutions per nucleotide position.
Genomic DNA of strains WR061 ${ }^{\mathrm{T}}$, WR054 and $P$. propionicum JCM $5830^{\mathrm{T}}$ was extracted according to the method described by Akasaka et al. (2003) and digested with P1 nuclease by using a YAMASA GC kit (Yamasa Shoyu). The G+C contents of their genomic DNA were measured by HPLC (Hitachi L-7400) equipped with a $\mu$ Bondapak C18 column $(3.9 \times 300 \mathrm{~mm}$; Waters $)$. The genomic DNA G+C content of strains WR061 ${ }^{\mathrm{T}}$ and WR054 were 69.5 and $69.3 \mathrm{~mol} \%$, respectively, and that of P. propionicum JCM $5830^{\mathrm{T}}$ was $65.3 \mathrm{~mol} \%$ (consistent with the values of $63-65 \%$ reported for this species; Schaal,

Table 1. Cellular fatty acid composition (\%) of strains WR061 ${ }^{\top}$ and WR054 and their closest relative, Propionibacterium propionicum JCM $5830^{\top}$

Strains: 1 , WR061 ${ }^{\mathrm{T}}$; 2, WR054; 3, Propionibacterium propionicum JCM $5830^{\mathrm{T}}$. - , Not detected; DMA, dimethylacetal. All data were obtained in this study.

\begin{tabular}{|lccc|}
\hline Fatty acid & $\mathbf{1}$ & $\mathbf{2}$ & $\mathbf{3}$ \\
\hline iso-C $14: 0$ & 2.3 & 1.6 & - \\
$\mathrm{C}_{14: 0}$ & 0.4 & 0.6 & 2.3 \\
iso-C $_{15: 0}$ & 7.5 & 8.6 & 31.0 \\
anteiso-C $15: 0$ & 33.7 & 34.6 & 32.5 \\
$\mathrm{C}_{15: 0}$ & 3.5 & 4.2 & 9.2 \\
iso-C ${ }_{15: 0}$ DMA & 4.7 & 5.6 & - \\
anteiso-C $15: 0$ DMA & 9.2 & 6.7 & - \\
$\mathrm{C}_{15: 0}$ DMA & 14.0 & 10.3 & - \\
$\mathrm{C}_{16: 0}$ & 0.4 & 1.6 & 2.3 \\
$\mathrm{C}_{16: 0}$ DMA & 3.2 & 5.0 & - \\
anteiso-C & - & - & 1.1 \\
$\mathrm{C}_{17: 0}$ & 0.5 & 1.0 & 1.4 \\
$\mathrm{C}_{17: 0}$ DMA & 7.2 & 4.2 & - \\
$\mathrm{C}_{19: 0}$ cyclo 9,10 DMA & - & - & 20.3 \\
\hline
\end{tabular}

${ }^{\star}$ Equivalent chain-length $=19.322$.
1986). Isoprenoid quinones were extracted as described by Komagata \& Suzuki (1987) and analysed by using a mass spectrometer (JMS-SX102A; JEOL). Menaquinone MK$9\left(\mathrm{H}_{4}\right)$ was the major respiratory quinone of the novel strains, which was the same as that of $P$. propionicum (Charfreitag et al., 1988). The diagnostic cell-wall diamino acids of strains WR061 ${ }^{\mathrm{T}}$, WR054 and P. propionicum JCM $5830^{\mathrm{T}}$ were analysed according to the method described by Akasaka et al. (2003). The amino acid of the two novel strains was meso-diaminopimelic acid (DAP), while that of P. propionicum JCM $5830^{\mathrm{T}}$ was LL-DAP (consistent with that reported for this species; Schaal, 1986).

Some differential cellular and physiological characteristics of P. propionicum JCM $5830^{\mathrm{T}}$, including cell morphology, cobalamin requirement and substrate utilization, were determined under the same conditions used for the characterization of strains WR061 ${ }^{\mathrm{T}}$ and WR054. P. propionicum JCM $5830^{\mathrm{T}}$ produced dense and rough colonies with greyish surfaces on PY4S agar slants. The colonies were composed of aggregates of distinctly long and branched, filamentous cells as reported in the description of this species (Schaal, 1986). Filamentous assemblages of cells did not occur in cultures of strains WR061 ${ }^{\mathrm{T}}$ and WR054. P. propionicum JCM $5830^{\mathrm{T}}$ did not require cobalamin for growth and produced acetate and propionate $(\sim 1: 2)$ from glucose irrespective of the presence or absence of cobalamin. $P$. propionicum JCM $5830^{\mathrm{T}}$ was also negative for catalase activity, whereas strains WR061 $1^{\mathrm{T}}$ and WR054 were catalasepositive. Differences in other characteristics including substrate utilization are shown in Table 2.

The significantly low $16 \mathrm{~S}$ rRNA gene sequence similarities between the two novel strains and their closest relatives, as well as the distinct differences in their cellular, physiological and chemotaxonomic characteristics, clearly indicate that strains $\mathrm{WR} 061^{\mathrm{T}}$ and WR054 represent a novel species of a new genus, for which the name Propioniciclava tarda gen. nov., sp. nov. is proposed. 
Table 2. Characteristics of strains $\mathrm{WR} 061^{\top}$ and $\mathrm{WR} 054$ and their closest relative, Propionibacterium propionicum JCM $5830^{\top}$

Strains: 1, WR061 ${ }^{\mathrm{T}}$; 2, WR054; 3, Propionibacterium propionicum JCM 5830 ${ }^{\mathrm{T}}$. All data were obtained in this study using the same methods for cultivation and analyses. I, irregular rods; S, slender rods; P, pleomorphic, filamentous rods; +, positive; w, weakly positive; -, negative.

\begin{tabular}{|c|c|c|c|}
\hline Characteristic & 1 & 2 & 3 \\
\hline Isolation source & Methanogenic reactor & Methanogenic reactor & Human \\
\hline Cell morphology & $\mathrm{I}, \mathrm{S}$ & I, S & $\mathrm{P}$ \\
\hline Cobalamin requirement & + & + & - \\
\hline Growth in $\mathrm{PY}\left(\mathrm{B}_{12}\right)$ medium without substrates & $\mathrm{w}$ & $\mathrm{w}$ & + \\
\hline Catalase & + & + & - \\
\hline Aesculin hydrolysis & + & + & - \\
\hline \multicolumn{4}{|l|}{ Acid production from } \\
\hline Cellobiose & + & + & - \\
\hline Melibiose & + & + & $\mathrm{W}$ \\
\hline Amygdalin & + & + & - \\
\hline Aesculin & + & + & - \\
\hline Salicin & + & + & - \\
\hline Pyruvate & $\mathrm{w}$ & $\mathrm{w}$ & + \\
\hline Lactate & w & W & + \\
\hline DNA G $+C$ content $(\mathrm{mol} \%)$ & 69.5 & 69.3 & 65.3 \\
\hline Diamino acid & meso-DAP & meso-DAP & LL-DAF \\
\hline
\end{tabular}

\section{Description of Propioniciclava gen. nov.}

Propioniciclava (Pro.pi.on.i.ci.cla'va. N.L. n. acidum propionicum propionic acid; N.L. fem. n. clava club; N.L. fem. Propioniciclava propionic acid-producing club).

Cells are facultatively anaerobic, Gram-reaction-positive, non-motile, non-spore-forming, irregular rods. Chemoorganotrophic. Ferments various carbohydrates and produces acetate and propionate from glucose. The diagnostic diamino acid in the peptidoglycan is meso-DAP. The major respiratory quinone is menaquinone $\mathrm{MK}-9\left(\mathrm{H}_{4}\right)$. The genomic DNA has a high $\mathrm{G}+\mathrm{C}$ content. The type species of the genus is Propioniciclava tarda.

\section{Description of Propioniciclava tarda sp. nov.}

Propioniciclava tarda ( $\operatorname{tar}^{\prime} \mathrm{da}$ L. fem. adj. tarda slow or inactive, referring to the slow growth of the type strain).

Possesses the following characteristics in addition to those described for the genus. Cobalamin (vitamin $B_{12}$ ) is an essential requirement for growth. In the absence of cobalamin, cells are irregular rods with tapered ends $(0.5-0.8 \times 0.6-1.8 \mu \mathrm{m})$ and occur singly or in short chains. In the presence of cobalamin, cells are slender irregular rods (3-6 $\mu \mathrm{m}$ long) with crescent-shaped arrangements. Growth is very slow, even in the presence of cobalamin. Grows under aerobic conditions. Grows at $20-37{ }^{\circ} \mathrm{C}$ (optimum $35{ }^{\circ} \mathrm{C}$ ) and $\mathrm{pH}$ 5.3-8.0, preferring slightly alkaline conditions (optimum $\mathrm{pH} 7.5$ ). Addition of $\mathrm{NaCl}$ to the medium inhibits growth. Positive for catalase and nitrate-reducing activities. Aesculin is hydrolysed. Oxidase, indole and hydrogen sulfide are not produced. Starch is not hydrolysed. Sensitive to bile. Utilizes fructose, galactose, glucose, cellobiose, lactose and salicin as preferable substrates. The final $\mathrm{pH}$ of media after growth with glucose is 4.8-4.9. Produces acetate and propionate with a small amount of succinate. Mannose, maltose, melibiose, sucrose, trehalose, melezitose, raffinose, mannitol, amygdalin, aesculin, pyruvate and lactate are also utilized with slow growth. Arabinose, ribose, xylose, rhamnose, sorbose, carboxymethylcellulose (CMC), cellulose (cellulose powder and filter paper), glycogen, inulin, starch, xylan, pectin, dulcitol, inositol, sorbitol, glycerol, ethanol, fumarate, malate and succinate are not utilized. Anteiso- $\mathrm{C}_{15: 0}$ and $\mathrm{C}_{15: 0}$ DMA are the major cellular fatty acids; $\mathrm{C}_{15: 0}$ and DMA type compounds are the major fatty acid constituents.

The type strain, WR061 ${ }^{\mathrm{T}}\left(=\mathrm{JCM} 15804^{\mathrm{T}}=\mathrm{DSM} 22130^{\mathrm{T}}\right)$, was isolated from a sample of rice-straw residue in a methanogenic reactor treating waste from cattle farms. The DNA G + C content of the type strain is $69.3-69.5 \%$.

\section{Acknowledgements}

This work was partly supported by a Grant-in-Aid from the Institute for Fermentation, Osaka, and also by the Project for Development of Technology for Analysing and Controlling the Mechanism of Biodegrading and Processing supported by the New Energy and Industrial Technology Development of Organization (NEDO). We are grateful to Y. Ohtaki for helpful assistance in the characterization of the strains.

\section{References}

Akasaka, H., Ueki, A., Hanada, S., Kamagata, Y. \& Ueki, K. (2003). Propionicimonas paludicola gen. nov., sp. nov., a novel facultatively anaerobic, Gram-positive, propionate-producing bacterium isolated from plant residue in irrigated rice-field soil. Int J Syst Evol Microbiol 53, 1991-1998. 
Akasaka, H., Ueki, K. \& Ueki, A. (2004). Effects of plant residue extract and cobalamin on growth and propionate production of Propionicimonas paludicola isolated from plant residue in irrigated rice field soil. Microbes Environ 19, 112-119.

Altschul, S. F., Madden, T. L., Schäffer, A. A., Zhang, J., Zhang, Z., Miller, W. \& Lipman, D. J. (1997). Gapped BLAST and PSI-BLAST: a new generation of protein database search programs. Nucleic Acids Res 25, 3389-3402.

Charfreitag, O., Collins, M. D. \& Stackebrandt, E. (1988). Reclassification of Arachnia propionica as Propionibacterium propionica comb. nov. Int J Syst Bacteriol 38, 354-357.

Cummins, C. S. \& Johnson, J. L. (1986). Genus I. Propionibacterium Orla-Jensen 1909, 337. In Bergey's Manual of Systematic Bacteriology, vol. 2, pp. 1346-1353. Edited by P. H. A. Sneath, N. S. Mair, M. E. Sharpe \& J. G. Holt. Baltimore: Williams \& Willkins.

Cummins, C. S. \& Moss, C. W. (1990). Fatty acid composition of Propionibacterium propionicum (Arachnia propionica). Int J Syst Bacteriol 40, 307-308.

Dolfing, J. (1988). Acetogenesis. In Biology of anaerobic microorganisms, pp. 417-468. Edited by A. J. B. Zehnder. NY: John Wiley \& Sons.

Felsenstein, J. (2006).PHYLIP (phylogeny inference package), version 3.66. Department of Genome Sciences, University of Washington, Seattle, USA.

Garrity, G. M. \& Holt, J. G. (2001). The road map to the manual. In Bergey's Manual of Systematic Bacteriology, 2nd edn, vol. 1, pp. 119166. Edited by D. R. Boone \& G. M. Garrity. NY: Springer.

Gerencser, M. A. \& Slack, J. M. I. (1967). Isolation and characterization of Actinomyces propionicus. J Bacteriol 94, 109-115.

Holdeman, L. V., Cato, E. P. \& Moore, W. E. C. (1977). Anaerobe Laboratory Manual, 4th edn. Blacksburg, VA: Virginia Polytechnic Institute and State University.

Komagata, K. \& Suzuki, K. (1987). Lipid and cell-wall analysis in bacterial systematics. Methods Microbiol 19, 161-207.

Kusano, K., Yamada, H., Niwa, M. \& Yamasato, K. (1997). Propionibacterium cyclohexanicum sp. nov., a new acid-tolerant $\omega$ cyclohexyl fatty acid-containing propionibacterium isolated from spoiled orange juice. Int J Syst Bacteriol 47, 825-831.

Miller, L. T. (1982). Single derivatization method for routine analysis of bacterial whole-cell fatty acid methyl esters, including hydroxy acids. J Clin Microbiol 16, 584-586.
Miyagawa, E., Azuma, R. \& Suto, E. (1979). Cellular fatty acid composition in Gram-negative obligately anaerobic rods. J Gen Appl Microbiol 25, 41-51.

Moore, L. V. H., Bourne, D. M. \& Moore, W. E. C. (1994). Comparative distribution and taxonomic value of cellular fatty acids in thirty-three genera of anaerobic Gram-negative bacilli. Int J Syst Bacteriol 44, 338-347.

Nishiyama, T., Ueki, A., Kaku, N. \& Ueki, K. (2009a). Clostridium sufflavum sp. nov., isolated from a methanogenic reactor treating cattle waste. Int J Syst Evol Microbiol 59, 981-986.

Nishiyama, T., Ueki, A., Kaku, N., Watanabe, K. \& Ueki, K. (2009b). Bacteroides graminisolvens sp. nov., a xylanolytic anaerobe isolated from a methanogenic reactor treating cattle waste. Int J Syst Evol Microbiol 59, 1901-1907.

Roth, J. R., Lawrence, J. G. \& Bobik, T. A. (1996). Cobalamin (coenzyme $\mathrm{B}_{12}$ ): synthesis and biological significance. Annu Rev Microbiol 50, 137-181.

Saitou, N. \& Nei, M. (1987). The neighbor-joining method: a new method for reconstructing phylogenetic trees. Mol Biol Evol 4, 406-425.

Schaal, K. P. (1986). Genus Arachnia Pine and Georg 1969, 269 ${ }^{\mathrm{AL}}$. In Bergey's Manual of Systematic Bacteriology, vol. 2, pp. 1332-1342. Edited by P. H. A. Sneath, N. S. Mair, M. E. Sharpe \& J. G. Holt. Baltimore: Williams \& Willkins.

Thompson, J. D., Higgins, D. G. \& Gibson, T. J. (1994). ClUSTAL W: improving the sensitivity of progressive multiple sequence alignment through sequence weighting, position-specific gap penalties and weight matrix choice. Nucleic Acids Res 22, 4673-4680.

Ueki, A., Matsuda, K. \& Ohtsuki, C. (1986). Sulfate reduction in the anaerobic digestion of animal waste. J Gen Appl Microbiol 32, 111-123.

Ueki, A., Abe, K., Kaku, N., Watanabe, K. \& Ueki, K. (2008). Bacteroides propionicifaciens sp. nov., isolated from rice-straw residue in a methanogenic reactor treating waste from cattle farms. Int J Syst Evol Microbiol 58, 346-352.

Ueki, A., Abe, K., Ohtaki, Y., Kaku, N., Watanabe, K. \& Ueki, K. (2011). Bacteroides paurosaccharolyticus sp. nov., isolated from a methanogenic reactor treating waste from cattle farms. Int J Syst Evol Microbiol 61, 448-453.

Wilkins, T. D., Wagner, D. L., Veltri, B. J., Jr \& Gregory, E. M. (1978). Factors affecting production of catalase by Bacteroides. J Clin Microbiol 8, 553-557. 